\title{
Non-Modifiable Risk Factors (Age and Sex), Stroke Types, and Outcomes in Rivers State, Nigeria: A Retrospective Hospital- Based Study
}

\author{
Osborne Ikechuckwu Osuegbu ${ }^{1}$, Foluke Olukemi Adeniji ${ }^{2}$, Golden Chukwuemaka Owhonda ${ }^{3}$, Rogers Bariture \\ Kanee 4, M Alblihed 5, Gaber El-Saber Batiha ${ }^{6}$, and Eric Osamudiamwen Aigbogun, Jr.7,8*
}

1 Department of Preventive and Social Medicine, Faculty of Clinical Sciences, College of Health Sciences, University of Port Harcourt, P.M.B 5323, Choba, Rivers State, Nigeria; osborneosuegbu@gmail.com.

2 Department of Preventive and Social Medicine, Faculty of Clinical Sciences, College of Health Sciences, University of Port Harcourt, P.M.B 5323, Choba, Rivers State, Nigeria; foluke.adeniji@uniport.edu.ng.

3 Department of Public Health Services, Rivers State Ministry of Health, 500001, Port Harcourt, Nigeria; goldenowhonda@yahoo.com.

4 Institute of Geo-Science and Space Technology, Rivers State University, P.M.B. 5080, Nkpolu Oroworukwo, Rivers State, Nigeria; kaneerogers34@gmail.com.

5 Department of Microbiology, College of Medicine, Taif University, P.O. Box. 11099, Taif 21944, Saudi Arabia; mabulihd@tu.edu.sa.

6 Department of Pharmacology and Therapeutics, Faculty of Veterinary Medicine, Damanhour University, Damanhour 22511, AlBeheira, Egypt; gaberbatiha@gmail.com.

7 Department of Public Health, Faculty of Sciences and Technology, Cavendish University Uganda, P.O Box 33145 Kampala (U), Uganda.

8 Center for Occupational Health and Safety, Institute of Petroleum Studies, University of Port Harcourt, P.M.B 5323, Choba, Rivers State, Nigeria; eric_aigbogun@uniport.edu.ng.

* Correspondence: FOA; foluke.adeniji@uniport.edu.ng, EOAJr.; eric_aigbogun@uniport.edu.ng.

\begin{abstract}
This study used structural equation modelling (SEM) to evaluate the direct effect of sex and age on stroke types and outcomes in Tertiary Health Facilities in Rives State, Nigeria. The study was a cross-sectional retrospective hospital-based research that utilized specific stroke patients' information between 2015-2019. The study obtained the sex and age, stroke type (ischemic/hemorrhagic), and outcomes (No disability/disability/death) from the records. The retrieved data was Microsoft Excel (2016), then analyzed using SPSS (version 21, Amos) and STATGRAPHICS centurion (Stat Point Tech., Inc.). From the result, out of the recorded 1916 stroke patients, 1229 (64.1\%) were female, while $687(35.9 \%)$ were males. The older adults ( $>55$ years) had more recorded cases ( $\mathrm{n}=1289)$ than young adults (ages 18-35 years; $n=77$ ) and middle-aged adults (ages $36-55$ years, $n=550$ ). The SEM results showed that age was significantly associated with stroke type $(\mathrm{P}<0.001)$ and outcomes $(\mathrm{P}=0.038)$, while sex was significantly associated with stroke outcomes $(\mathrm{P}<0.001)$. The likelihood of death was $1.3 \times$ higher in hemorrhagic stroke than ischemic stroke. In conclusion, age and sex had direct effects on stroke type, while age had a direct effect on stroke outcome. Hemorrhagic stroke was more likely to cause death than ischemic stroke in the studied population.
\end{abstract}

Keywords: Age; Sex; Stroke Types; Outcomes; SEM; Tertiary Hospitals; Rivers State.

\section{Introduction}

The subject of stroke can be traced back to 460 - 370 preceding the Common Era and was first referred to as 'Apoplexy' by Hippocrates due to the physical symptoms of spasms and loss of motion [1], [2]. Although the nomenclature by Hippocrates suggests physical changes that occur in stroke patients, but not necessarily cerebral function disturbances associated with stroke [3]. It was only until the last half of the seventeenth century, that Jakob Wepfer and Thomas Willis highlighted blood supply disruption in the brains of people diagnosed with Apoplexy, thus, providing the most important advances in the 
understanding of stroke [3]-[5]. Apoplexy was further described as blocked carotid or vertebral artery in some cases, and bleeding into the brain in others [3], [6]. However, in 1689 the word 'Stroke' was introduced into medicine by William Cole [7], [8].

Stroke which is defined as focal neurological deficit of a vascular origin [9]-[11] is the second-leading single cause of death in the world and the third leading cause of premature morbidity and mortality as measured by disability adjusted life years (DALY) according to WHO [11]-[14], closely behind ischemic heart disease [11], [14]-[19]. Surprisingly, the proportion appears underestimated [20], [21] and the consequence on patients and their families is often unexplainable, and sometimes referred to as tragic [22], [23] because of the enormous psychological, social, and financial burden [6], [24].

The burden of stroke is likely to increase in low-and middle-income countries because of the ongoing epidemiological transition [25], [26]; however, the people of African descent are suggested to be the most predisposed to stroke at a younger age, with the worst outcomes [27], [28]. Evidence from community-based study suggest that the agestandardized annual stroke incidence in Africa was up to 316 per 100,000 [29]. In SubSaharan Africa (SSA), a good number of hospitals register a high incidence of stroke death, with more than $30 \%$ of patients dying within the first month of onset [17], [30]-[32]. From a community-based survey, the estimated prevalence of stroke was about 300 cases per 100,000 population in SSA; affecting mainly young people [13], [24], [29]. Incidentally, epidemiological information on stroke in SSA remains a challenge because available data are often fragmented arising from inadequacies in registries, facilities, poor access to care, and lack of specialists [36]. In Nigeria, the prevalence ranges from 0.58 to 13.31 per 1,000 persons [25], [26], [33]-[35]. The annual mortality rate increased with age from 0.70/1,000 to $15.19 / 1,000$ per year in the eighth decade [34].

On the basis of imaging findings stroke is divided into two [37]; ischemic and hemorrhagic stroke [6], [8], [12], [37]-[40]. Ischemic stroke arises from blocked artery, which could be because of an embolus or thrombosis that interrupts the flow of oxygen to the brain, while hemorrhagic stroke is simply due to a blowout or breakage of a blood vessel in the brain which can either be intracerebral or subarachnoid [3], [21], [41]-[43]. According to Avan et al., the global number of those diagnosed with ischemic stroke doubled between 1990 and 2017 [44]. In 2013 alone, 10.3 million new stroke cases were reported with $67 \%$ ischemic stroke [45]. Of the 6.5 million stroke deaths, $51 \%$ were caused by ischemic stroke. Additionally, out of the 25.7 million stroke survivors, $71 \%$ had ischemic stroke [45]. On the other hand, Katan and Luft found that hemorrhagic stroke was responsible for more death and disability-adjusted life-years lost (DALYs) worldwide [46].

Furthermore, data obtained from the INTERSTROKE study involving 22 countries indicates that in African countries [47], the gap between those diagnosed with ischemic and hemorrhagic stroke were about $66 \%$ and 34\%, respectively [29], [47], [48]. In Nigeria and Ghana, the percentage of individuals confirmed to have ischemic stroke was $68 \%$ and hemorrhagic stroke $32 \%$ whereas in high income countries the percentage was significantly higher for ischemic stroke (91\%) and lower for hemorrhagic stroke (9\%) [6], [31]. Additionally, when the two subtypes of hemorrhagic strokes were compared, the incidence of intracerebral hemorrhage was higher than subarachnoid hemorrhage [49]. Intracerebral stroke accounts for $80 \%$ of hemorrhagic stroke [6]. Studies that compared the incidence of TIA with the types of stroke suggested that the incidence of TIA was lower than ischemic stroke but higher than hemorrhagic stroke [47], [49].

There are two types of risk factors associated with stroke: modifiable and non-modifiable [13], [50]-[52]. The modifiable risk factors are often adjustable and associated with the individual's lifestyle which includes high cholesterol, smoking, lack of physical activity, and poor diet, alcohol consumption, stress, obesity, diabetes, heart disease, and hypertension [6], [7], [56], [13], [47], [50]-[55]. On the other hand, the non-modifiable risk factors are usually beyond the individual's control and include gender, age, genetics and ethnicity [51]-[53], [57]. According to reports from the INTERSTROKE study, around 90\% of the global stroke burden is brought about by ten modifiable risk factors [6], [58], [59]. A recent systematic review showed that among the modifiable risk factors, hypertension 
and diabetes were identified as the main danger components of stroke [60]-[62]. For nonmodifiable factors, the relationship between stroke and age, sex, and ethnicity remain nonlinearly correlated [53], [57], while genetic predisposition has a significant correlation with stroke [53], [63], [64].

Although there is a lot of the hospital-based study confirming a high prevalence of stroke in Nigeria [65]; however, there is still epidemiological gaps in stroke characteristics and its distribution in Nigerian populations and subpopulations, specifically among South-South populations. On this background, this study employed SEM to evaluate the role of age and sex as non-modifiable risk factors for stroke types and outcomes in Rivers State; relying on the evidence from retrospective hospital data.

\section{Materials and Methods}

\subsection{Study Design}

This was a five-year (Jan 2015-Dec 2019) hospital-based retrospective, analytical study conducted at the Rivers State University Teaching Hospital (RSUTH) and University of Port Harcourt Teaching Hospital (UPTH), the two tertiary health facilities in Rivers State, Nigeria. The study was carried out from 15th May 2019 to 31st February 2020. The study was conducted in line with the ethical declaration of Helsinki [66]. During the research, the ensured that anonymity and confidentiality was upheld to the highest standard.

\subsection{Study Framework}

The conceptual model for this study was developed on the background of theoretical constructs and empirical evidence of sex and age as factors for stroke cases and outcomes [11], [15], [72]-[76], [41], [59], [61], [67]-[71]. Studies have shown that stroke types (ischemic/hemorrhagic) are associated with stroke outcomes (no-disability/disability/death) [6], [7], [45], [69], [76], [77] and it can be influenced by non-modifiable risk factors such as age and sex [6], [13], [53], [70], [78].

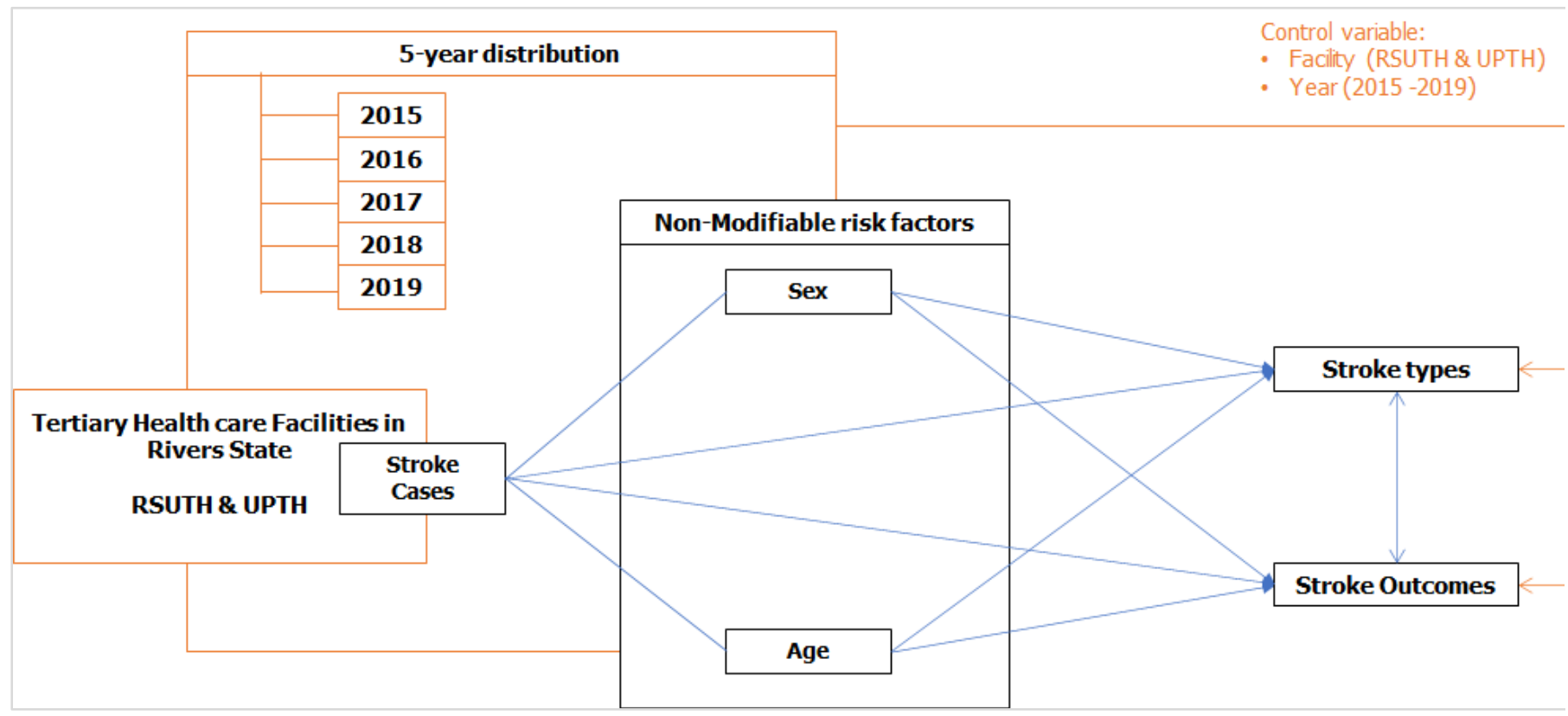

Figure 1: Construct model for assessing the stroke cases and structure in tertiary health facilities in Rivers State

The study conceptualized that the common non-modifiable factors (age and sex) have direct effect on stroke types and outcomes. The construct is based on the hypothesis that stroke types and outcomes will differ (1) between the sex and (2) among age categories in the studied population, and (3) there is a significant association between stroke 
types and outcomes. The study controlled for facility (RUSTH and UPTH) and the years (2015-2019) the data were collected (Figure 1).

\subsection{Data Collection}

Stroke data were retrieved from the archives (2015 to 2019) of RSUTH and UPTH. The collected data were categorized into three age groups; young adults (ages 18-35 years; $\mathrm{n}=77$ ), middle-aged adults (ages $36-55$ years, $\mathrm{n}=550$ ), and older adults (aged older than 55 years, $n=1289$ ); sex into male (687) and female (1229). The stroke cases were categorized based on types (ischemic or hemorrhagic) and outcomes (no disability, disability, or death).

\subsection{Data Management and Analysis}

The obtained data was managed in Microsoft Excel 2016 and transferred to STATGRAPHICS centurion CVI version 16 (Stat Point Tech., Inc.) and Statistical Package for the Social Sciences (SPSS) version 23 (IBM, Amos, USA) for analysis. SPSS descriptive statistics; median (percentile) for continuous variables and frequencies (percentages) for categorical variables were used to describe the data distributions. Pearson's Chi-square (Yates correction) analysis evaluated the association of sex, age, and stroke type and outcome after hospitalization.

SPSS-Amos structural equation modelling (SEM) using direct path analysis evaluate the relationship between sex \& age, and the stroke type and outcomes. The study controlled for facility and years from which the data were retrieved. To justify for the nonnormal distribution of the model variables, we used the maximum likelihood with robust standard errors (MLR) as the estimator. The study considered fit indices to assess the fit of the models: (i) The goodness of fit index (GFI) under generalized least squares (GLS) [79] and (ii) Bentler's comparative fit index (CFI) [80]. Values between 0.90 and 1.0 on Bentler's CFI and value $\geq 0.95$ on the GFI suggests the model provides a good fit to the data [81]. The study also determined the standardized and unstandardized direct effects of the predictor variables on the response variables. Multinomial logistics regression analysis was used to determine the relative difference in the predictor variables in the SEM model. The confidence level for all analysis was set at $95 \%$ and p-value less than 0.05 were considered significant.

\section{Results}

\subsection{Presentation of Results}

The descriptive characteristics of the study demography is presented in Table 1 . The graphical representation 5-year (2015-2019) distribution of stroke cases stratified by sex, age group, type, outcome after hospitalization is presented in Figure 2.

Table 2 represents an association between study demographics and stroke types, while Table 3 represents the association between the study demographics and hospitalization outcome. Using SEM, the result of the analysis is presented in Figure 3. Multinomial logistics regression analysis in Table $4 \& 5$ evaluated the difference in the effects of the significant terms in the SEM.

\subsection{Interpretation of Results}

From the result in Table 1, both facilities had more female cases of stroke (RSUTH 718; 79.7\% and UPTH - 511; 50.3\%) compared to males (RSUTH; 183 [20.3\%] and UPTH; $504[49.7 \%]$ ). The age grouping indicated that the older adults ( $>55$ years) predominated the stroke cases $(1289 ; 67 \%)$ with $647(71.8 \%)$ in RSUTH and $642(63.3 \%)$ in UPTH. The middle-aged adult also had some recognizable cases $(550 ; 28.7 \%)$ in RSUTH $(221 ; 24.5 \%)$ and UPTH $(329 ; 32.4 \%)$.

Table 1. Descriptive characteristics of observed study variables.

\begin{tabular}{lll} 
Variables & Facility & Total (\%) \\
\hline
\end{tabular}




\begin{tabular}{|c|c|c|c|}
\hline & RSUTH (\%) & UPTH (\%) & \\
\hline \multicolumn{4}{|l|}{ Year } \\
\hline 2015 & $205(22.8)$ & $211(20.8)$ & $416(21.7)$ \\
\hline 2016 & 159 (17.6) & 155 (15.3) & $314(16.4)$ \\
\hline 2017 & $122(13.5)$ & $191(18.8)$ & 313 (16.3) \\
\hline 2018 & $172(19.1)$ & $226(22.3)$ & $398(20.8)$ \\
\hline 2019 & $243(27.0)$ & $232(22.9)$ & $475(24.8)$ \\
\hline \multicolumn{4}{|l|}{ Sex } \\
\hline Male & $183(20.3)$ & 504 (49.7) & 687 (35.9) \\
\hline Female & 718 (79.7) & $511(50.3)$ & $1229(64.1)$ \\
\hline \multicolumn{4}{|l|}{ Age group } \\
\hline$=$ or $<35$ years & $33(3.7)$ & $44(4.3)$ & $77(4.0)$ \\
\hline 36 to 55 years & $221(24.5)$ & $329(32.4)$ & $550(28.7)$ \\
\hline$=$ or $>56$ years & $647(71.8)$ & $642(63.3)$ & 1289 (67.3) \\
\hline \multicolumn{4}{|l|}{ Stroke type } \\
\hline Hemorrhagic & $207(23.0)$ & $214(21.1)$ & $421(22.0)$ \\
\hline Ischemic & $694(77.0)$ & 801 (78.9) & 1495 (78.0) \\
\hline \multicolumn{4}{|l|}{ Outcome } \\
\hline No Disability & 468 (51.9) & $167(16.5)$ & $635(33.1)$ \\
\hline Disability & $175(19.4)$ & $554(54.6)$ & $729(38.0)$ \\
\hline Death & $258(28.6)$ & $294(29.0)$ & $552(28.8)$ \\
\hline
\end{tabular}

From Figure 2, (A) the increase in stroke cases for males continued to rise from 2016 to 2018 which was steady to 2019, while there was a reduction in the cases between 2016 and 2017, then a steady rise through 2019. (B) There was a similar distribution pattern for middle-aged and older adults from 2015 through 2019, while younger adults had a sharp fall in the incidence of stroke from 2015 through 2017, with an increase which steadied out through 2019. (C) There was a steady rise in the cases of ischemic stroke from 2016 to 2019, after an initial decrease in 2015, while hemorrhagic stroke cases fluctuated across the years; with the lowest record in 2017. 


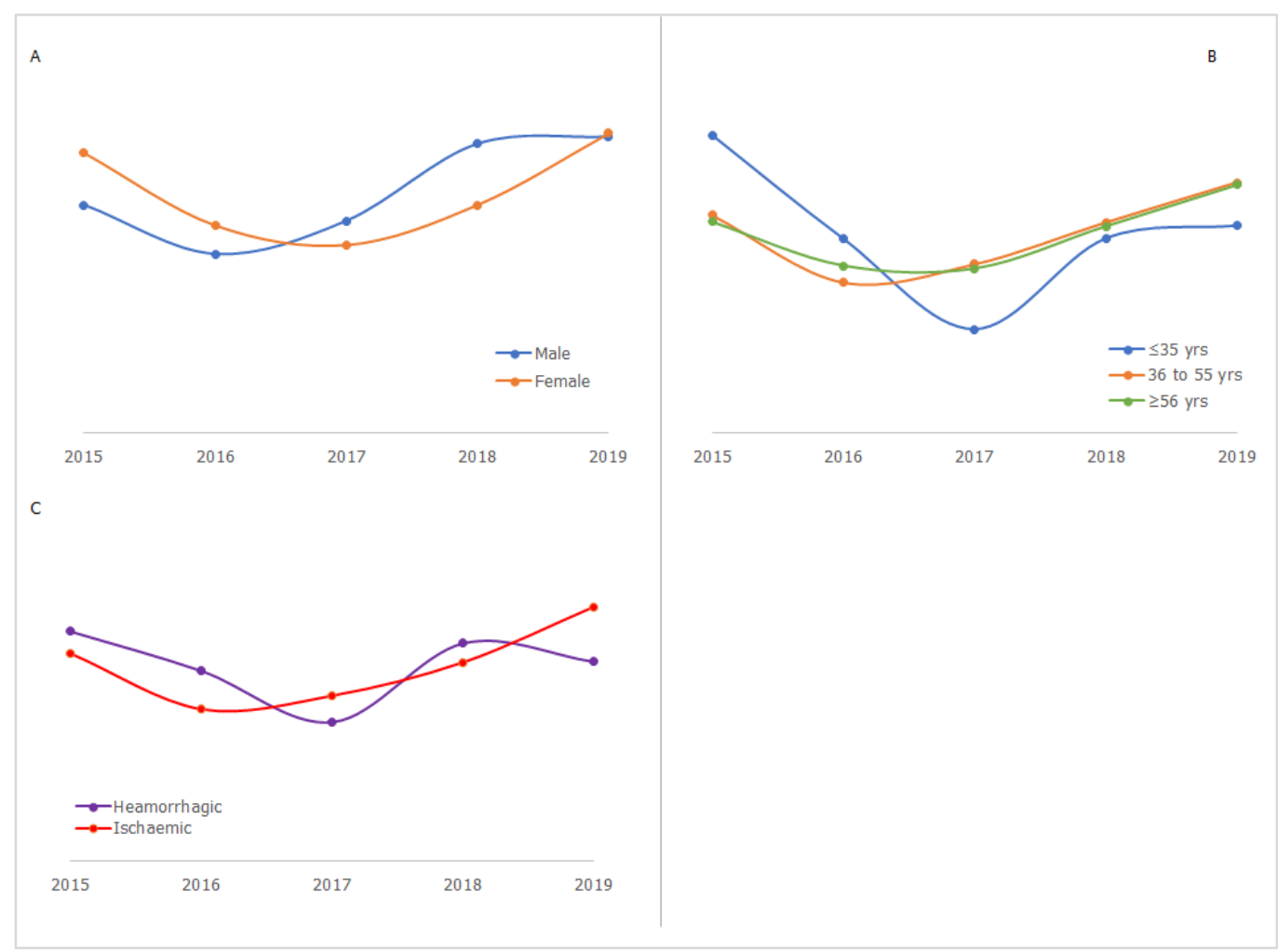

Figure 2. 5-year (2015-2019) distribution of stroke cases stratified by (A) sex (B) age group (C) stroke types

Table 2 and 3 show the test of association between the study variables. In Table 2, there was significant association between the stroke type and sex $\left(\chi^{2}=4.075 ; P=0.039\right)$, age group $\left(\chi^{2}=35.621 ; \mathrm{P}<0.001\right)$, and stroke type $\left(\chi^{2}=10.158 ; \mathrm{P}=0.0002\right)$. There was no association between the health facility and type of stroke $(\mathrm{P}>0.05)$. The results in Table 3 indicates a significant association between hospitalization outcome and facility $\left(\chi^{2}=336.473 ; \mathrm{P}<0.001\right)$, sex $\left(\chi^{2}=242.862 ; \mathrm{P}<0.001\right)$, age group $\left(\chi^{2}=16.742 ; \mathrm{P}=0.0022\right)$, and stroke type $\left(\chi^{2}=17.052\right.$; $\mathrm{P}=0.0002)$.

Table 2. Stroke types and study demographics.

\begin{tabular}{|c|c|c|c|c|c|}
\hline \multirow{2}{*}{ Variables } & \multicolumn{2}{|c|}{ Stroke type } & \multicolumn{3}{|c|}{ Chi-square test } \\
\hline & Hemorrhagic & Ischemic & $d f$ & $X^{2}$-value $(Y t)$ & P-value \\
\hline \multicolumn{6}{|l|}{ Sex } \\
\hline Female & $252(20.5)$ & $977(79.5)$ & \multirow{2}{*}{1} & \multirow{2}{*}{4.075} & \multirow{2}{*}{0.044} \\
\hline Male & $169(24.6)$ & $518(75.4)$ & & & \\
\hline \multicolumn{6}{|l|}{ Age group } \\
\hline$=$ or $<35$ years & $26(33.8)$ & $51(66.2)$ & \multirow{3}{*}{1} & \multirow{3}{*}{35.621} & \multirow{3}{*}{$<0.001$} \\
\hline 36 to 55 years & $162(29.5)$ & $388(70.5)$ & & & \\
\hline$=$ or $>56$ year & $233(18.1)$ & $1056(81.9)$ & & & \\
\hline
\end{tabular}

Table 3. Stroke types and study demographics.

\begin{tabular}{lllllll}
\hline \multirow{2}{*}{ Variables } & \multicolumn{3}{c}{ Hospitalization outcome } & \multicolumn{2}{c}{ Chi-square test } \\
& No Disability (\%) & Disability (\%) & Death (\%) & $d f$ & $X^{2}$-value (Yt) & P-value \\
\hline Sex & & & & & & \\
Female & $539(28.1)$ & $324(16.9)$ & $366(19.1)$ & 2 & 242.862 & $<0.001$ \\
Male & $96(5.0)$ & $405(21.1)$ & $186(9.7)$ & &
\end{tabular}


Age group

\begin{tabular}{|c|c|c|c|c|c|c|}
\hline$=$ or $<35$ years & $21(1.1)$ & $41(2.14)$ & $15(0.78)$ & \multirow{3}{*}{4} & \multirow{3}{*}{16.742} & \multirow[b]{2}{*}{0.002} \\
\hline 36 to 55 years & $187(9.8)$ & 227 (11.9) & $136(7.1)$ & & & \\
\hline$=$ or $>56$ years & $427(22.3)$ & $461(24.1)$ & 401 (20.9) & & & \\
\hline \multicolumn{7}{|l|}{ Stroke type } \\
\hline Hemorrhagic & $151(35.9)$ & $125(29.7)$ & $145(34.4)$ & \multirow{2}{*}{2} & \multirow{2}{*}{17.052} & \multirow{2}{*}{0.0002} \\
\hline Ischemic & $484(32.4)$ & $604(40.4)$ & $407(27.2)$ & & & \\
\hline
\end{tabular}

The study used SEM in evaluating the strength of the relationship between the variables after controlling for multicollinearity and non-normally distributed data. The GFI and the Bentler's CFI for the model fitness were 0.982 and 0.739 , respectively. The small value for CFI is associated with the large sample size $(n=1916)$ which according to Cochran indicates a disagreement between the theory and data $\left(\chi^{2}[\mathrm{df}=4]=107.043, \mathrm{P}<0.001\right)$; of which such departure is almost certainly detectable in data with large samples [82], [83].

The reconstructed path diagram with the standardized regression coefficients is depicted in Figure 3. The results showed that age was significantly associated with stroke type $(\mathrm{P}<0.001)$ and outcomes $(\mathrm{P}=0.038)$, while sex was significantly associated with stroke outcomes $(\mathrm{P}<0.001)$. There was no relationship between the stroke type and outcome $(\mathrm{P}=0.428)$. The standardized (z-statistic) and unstandardized direct effects are shown in the Appendix (Fig. A1 and Table A1).

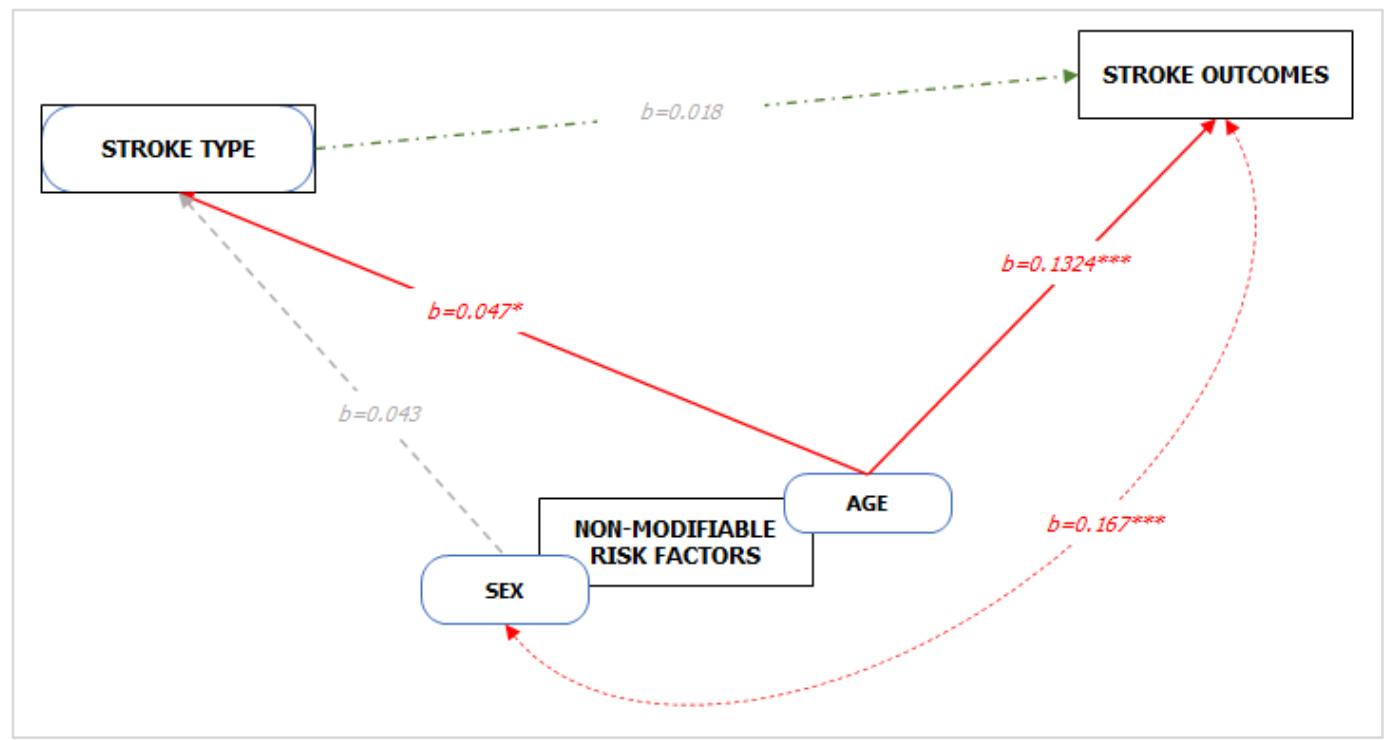

Figure 3. Standardized Pathways (z-statistic) for the relationship between sex, age, stroke types, and outcomes (1) red indicates significant path with ${ }^{*} P<0.05,{ }^{* * *} P<0.001$ (2) [See Appendix; Fig. A1 for the unedited SPSS-Amos output].

The multinomial logistics regression analyses were presented in Table $4 \& 5$. The Goodness-of-Fit analysis indicated that the models fit the data for Stroke Types $\left(\chi^{2}=4.524\right.$, $\mathrm{P}=0.104)$ and outcomes $\left(\chi^{2}=10.393, \mathrm{P}=0.733\right)$. The parameter estimates (model coefficients) in Table 4 indicates that age group was significantly associated with stroke type. That is, older adults ( $\geq 55$ years) were 1.9 times and 2.3 times more likely to have ischemic stroke than middle-aged adults ( 36 to 55 years) and younger adults ( $\leq 35$ years), respectively.

Table 4. Logistic regression model for stroke types and, sex and age.

\begin{tabular}{lllllll}
\hline $\begin{array}{l}\text { Parameter } \\
\text { Estimates }\end{array}$ & B & S.E & Wald & df & P-value & OR [95\% C.I] \\
\hline Intercept & -1.584 & 0.084 & 356.6 & 1 & $<0.001$ &
\end{tabular}




\begin{tabular}{lllllll} 
Male & 0.206 & 0.115 & 3.228 & 1 & 0.072 & $1.229[0.981-1.539]$ \\
S35 years & 0.853 & 0.252 & 11.45 & 1 & 0.001 & $2.346[1.432-3.845]$ \\
36 to 55 years & 0.623 & 0.119 & 27.55 & 1 & $<0.001$ & $1.864[1.477-2.352]$ \\
\hline
\end{tabular}

Note: (1) Reference variables [Response; Ischaemic stroke, Predictor; Sex=Female, Age group $=255 y e a r s]$. (2) Goodness-ofFit $\left[\chi^{2}=4.524, P=0.104\right], B$ - unstandardized regression weight, S.E - standard error of $B, d f-$ Degree of freedom, OR Odd ratio, C.I - Confidence Interval (3) Values in red indicate statistical significance

The parameter estimates (model coefficients) in Table 5 indicates that sex, age group, and stroke types were significantly associated with stroke outcome following hospitalization $(\mathrm{P}<0.05)$. When comparing the outcome for females and males following hospitalization from stroke, males were almost 3 times more likely to die than have no disability compared to females. On the other hand, females were more 2.6 time more likely to die than have disability compared to males. Older adults ( $\geq 55$ years) were 1.4 times and 1.2 times more likely to die than have no disability compared to middle-aged adults (36 to 55 years) and younger adults ( $\leq 35$ years), respectively. When comparing death and disability outcomes, the likelihood that older adults ( $\geq 55$ years) will die than have disability following hospital admission for stroke were 1.5 times and 3.1 times compared to middle-aged adults ( 36 to 55 years) and younger adults ( $\leq 35$ years), respectively. Hemorrhagic stroke was 2 times more likely to cause death than disability when compared to ischemic stroke.

Table 4. Logistic regression model for stroke types and, sex and age.

\begin{tabular}{|c|c|c|c|c|c|c|}
\hline $\begin{array}{l}\text { Parameter } \\
\text { Estimates }\end{array}$ & B & S.E & Wald & df & P-value & OR $[95 \%$ C.I $]$ \\
\hline \multicolumn{7}{|l|}{ No Disability } \\
\hline Intercept & 0.317 & 0.082 & 15.13 & 1 & $<0.001$ & \\
\hline Male & -1.063 & 0.144 & 54.63 & 1 & $<0.001$ & $0.345[0.261-0.458]$ \\
\hline$\leq 35$ years & 0.217 & 0.348 & 0.389 & 1 & 0.533 & $1.243[0.628-2.460]$ \\
\hline 36 to 55 years & 0.338 & 0.136 & 6.175 & 1 & 0.013 & $1.402[1.074-1.830]$ \\
\hline Haemorrhagic & -0.098 & 0.139 & 0.499 & 1 & 0.48 & $0.907[0.691-1.190]$ \\
\hline \multicolumn{7}{|l|}{ Disability } \\
\hline Intercept & -0.142 & 0.088 & 2.582 & 1 & 0.108 & \\
\hline Male & 0.951 & 0.119 & 63.42 & 1 & $<0.001$ & $2.589[2.049-3.273]$ \\
\hline$\leq 35$ years & 1.122 & 0.317 & 12.55 & 1 & $<0.001$ & $3.071[1.651-5.714]$ \\
\hline 36 to 55 years & 0.39 & 0.133 & 8.569 & 1 & 0.003 & $1.476[1.137-1.916]$ \\
\hline Haemorrhagic stroke & -0.735 & 0.145 & 25.82 & 1 & $<0.001$ & $0.479[0.361-0.637]$ \\
\hline
\end{tabular}

\section{Discussion}

Disruption of blood supply to the brain tissue leads to stroke [3], [39], [84], with two major types; ischemic stroke which results from interrupted blood supply to the brain (ischemic stroke) and haemorrhagic stroke caused by bleeding into or around the brain due to a ruptured artery [3], [13], [58], [78], [85]. Nevertheless, there is often a small-scale stroke attack before the occurrence of ischaemic or haemorrhagic stroke, and it is referred to as transient ischemic attack (TIA) [35], [56], [72], [74], [86], [87].

In this study, ischaemic stroke $(78.0 \%)$ was the most common type of stroke at the health facilities each year from 2015 to 2019. The case-distribution for ischaemic was $76.2 \%, 73.9 \%, 80.8 \%, 76.4 \%$, and $81.9 \%$, while haemorrhagic stroke was $23.8 \%, 26.1 \%$, $19.2 \%, 23.6 \%$, and $\% 18.1$ for the years $2015,2016,2017,2018$, and 2019 respectively. TIA was not captured in the records of the hospital. Surprisingly, only a few studies found TIA within the records of Nigerian hospitals [35], [88]. The distribution of stroke cases suggests a rise in hospitalisation from ischaemic stroke and a high incidence of 
hemorrhagic within the study environs. Studies have reported varying finding about the most common stroke type [6], [13], [21], [26], [29], [33], [63]. According to the Global Burden of Disease Study 2016, Asia and Sub-Sharan Africa had the least reduction in stroke cases across the globe [89]. Evidence from Stroke Investigative Research and Educational Network (SIREN) study undertaken in Nigeria and Ghana suggests that those confirmed with ischemic stroke was $68 \%$ higher than haemorrhagic stroke cases [90]; whereas, in high-income countries ischemic stroke contribute to $91 \%$ of stroke cases while the remaining $9 \%$ are haemorrhagic stroke [6].

There were more females $(1229 ; 64.1 \%)$ with stroke compared to males $(687 ; 35.9 \%)$ in this study. Studies in the United States found that women experience approximately 55,000 more strokes each year [91], [92], which has been linked to higher life expectancy, hormonal changes, use of contraceptives, and variable risk factors in women [93]-[96]. On the premise of non-modifiable risk factors; age and sex associated with stroke [21], [30], [99], [100], [35], [53], [54], [57], [63], [76], [97], [98], this study found that age group but not sex had direct effect on the stroke type. While the initial analysis found some association between sex and stroke type, the SEM after controlling for several factors, found no significant direct effect. Nevertheless, noteworthy was the distributional difference such that more males had haemorrhagic stroke $(24.6 \%)$ compared to females with ischaemic stroke $(79.5 \%)$. Specifically, for ischemic stroke, there are evidence from in-vivo and in-vitro studies demonstrating the role sex plays on the epidemiology, pathophysiology, and treatment efficacy of ischemic stroke [67], [69], [70], [101]. When comparing the hospitalisation outcome for females and males as a result of stroke, males were more likely to die than not have abnormality. The outcome "death" in males is not surprising as the record showed they had more of haemorrhagic stroke compared to females. Haemorrhagic stroke has been associated with more deaths compared to ischaemic stroke [13], [46], [73], [74], [102].

The findings of the study indicates that the outcome after an ischaemic stroke favoured males in comparison to females [69]-[71], and the reason was highlighted in a clinical trial study that found that minocycline, an anti-apoptotic agent, enhances treatment outcome following ischemic stroke in males, but not females [103]-[105]. For haemorrhagic stroke, there is little evidence about sex-associated risk factors. In this study, there was higher proportion of male $(24.6 \%)$ with haemorrhagic stroke compared to females $(20.5 \%)$. Conversely, a recent study found that the risk of subarachnoid haemorrhage is greater in women of average age than in men [68]. The possible reason is that the risk in women across their lifespan changes; as younger will most possibly be on oral contraceptives (OCP) and the loss of the protective effect from endogenous oestrogen in postmenopausal women, which puts them at a higher risk of thrombotic events [68].

In this study, age was distinctively linked to the stroke type and outcome. Similar to the suggestion by international stroke centre [106], over three-quarter of the stroke cases in this study were among the older adults (>56years). The global summary data showed that the prevalence of stroke in older adults is more than three times in middle aged and younger adults [41]. This study notes that studies have avoided analysing age as a standalone dependent variable for the development of stroke [41], [87], [107]; as biological function changes are significantly associated with age. However, age itself is an important, non-modifiable risk factor for ischemic stroke [70]. Younger adults had higher proportion haemorrhagic stroke (33.8\%) compared to middle aged $(29.5 \%)$ and older adults (18.1\%). This finding has been recently explained as a factor closely linked to behaviour; as younger men are less likely to seek professional care for presumed "mild" symptoms [68]. The older adults ( $\geq 55$ years) were more likely to have ischaemic stroke than middle-aged adults (36 to 55 years) and younger adults ( $\leq 35$ years) and older adults were more likely to die compared to middle-aged adults and younger adults following hospitalisation for stroke. Studies have shown that older adults are at risk of death following a stroke [6], [65], [77], [88], [94], [108], [109].

When our study compared stroke type and outcome, haemorrhagic stroke was 2 times more likely to cause death compared to ischaemic stroke. In a study by Avan et al. 
they found that ischemic stroke doubled between 1990 to 2017. And as at 2013 alone, there were 10.3 million new stroke cases with $67 \%$ ischemic stroke and $51 \%$ of death being those arising from ischemia [44]. El-Hajj et al. found out that in the Middle East, 71\% of 25.7 million stroke survivors had ischemic stroke and with higher disability adjusted life years (DALY) [45]. Katan and Luft found that haemorrhagic stroke was responsible for more death and DALY worldwide [46].

\section{Conclusions}

In the studied population, ischemic stroke was the most observed stroke type, but the proportion accounting for hemorrhagic stroke remained worryingly above the global average. Age has a significant influence on the type and outcome of stroke, while sex only influenced outcome - with males having better outcomes from ischemic stroke. The older adults dominated the stroke incidence and were more likely to die from a stroke irrespective of the type of stroke; however, younger adults had a more hemorrhagic stroke when compared to middle-aged and older adults. Hemorrhagic stroke was more likely to cause death than ischemic stroke.

Study Limitations: The study recognises that there are other non-modifiable risk factors which are associated with stroke type and outcomes. For this reason, the authors advocate for a robust and integrated hospital management information system (HMIS) for the African continent to enable holistic personal information documentation and history taking.

Author Contributions: Conceptualization, O.I.O., F.O.A., and E.O.A.Jr.; methodology, O.I.O., R.B.K., E.O.A.Jr.; software, R.B.K., E.O.A.Jr., G.EL-S.B.; validation, F.O.A., G.C.O., R.B.K., M.A., and G.EL-S.B.; data collection, O.I.O., and E.O.A.Jr.; formal analysis, E.O.A.Jr.; resources, O.I.O., M.A., and G.EL-S.B.; writing - original draft preparation, O.I.O., and E.O.A.Jr.; writing-review and editing, F.O.A., G.C.O., R.B.K., M.A., and G.EL-S.B.; visualization, O.I.O., R.B.K., and E.O.A.Jr.; supervision, F.O.A., project administration, O.I.O., F.O.A., and E.O.A.Jr.; funding acquisition, O.I.O., M.A., G.EL-S.B. All authors have read and agreed to the published version of the manuscript.

Funding: This research received no external funding

Institutional Review Board Statement: The study was conducted according to the guidelines of the Declaration of Helsinki, and approved by the Institutional Review Board of the University of Port Harcourt (Ref no: UPH/CEREMAD/REC/MM61/037), Rives State University of Teaching Hospital (Ref no: RSUTH/REC/2020037), and University of Port Harcourt Teaching Hospital (Ref no: UPTH/ADM/90/S.II/VOL.XI/848).

Data Availability Statement: The data set for this study was deposited in Harvard Dataverse and it is available at https://dataverse.harvard.edu/dataset.xhtml?persistentId=doi:10.7910/DVN/JWRXQI.

Acknowledgments: The authors acknowledge the co-operation of the Heads of Department of Internal Medicine at Rivers State University Teaching Hospital and University of Port Harcourt Teaching Hospital for granting permission to obtain the requisite data for this work and the contributions of the Heads of Nurses and medical records staff at both facilities for their assistance in the collection of data and unlimited access to their facilities.

Conflicts of Interest: The authors declare no conflict of interest.

\section{Appendix A}




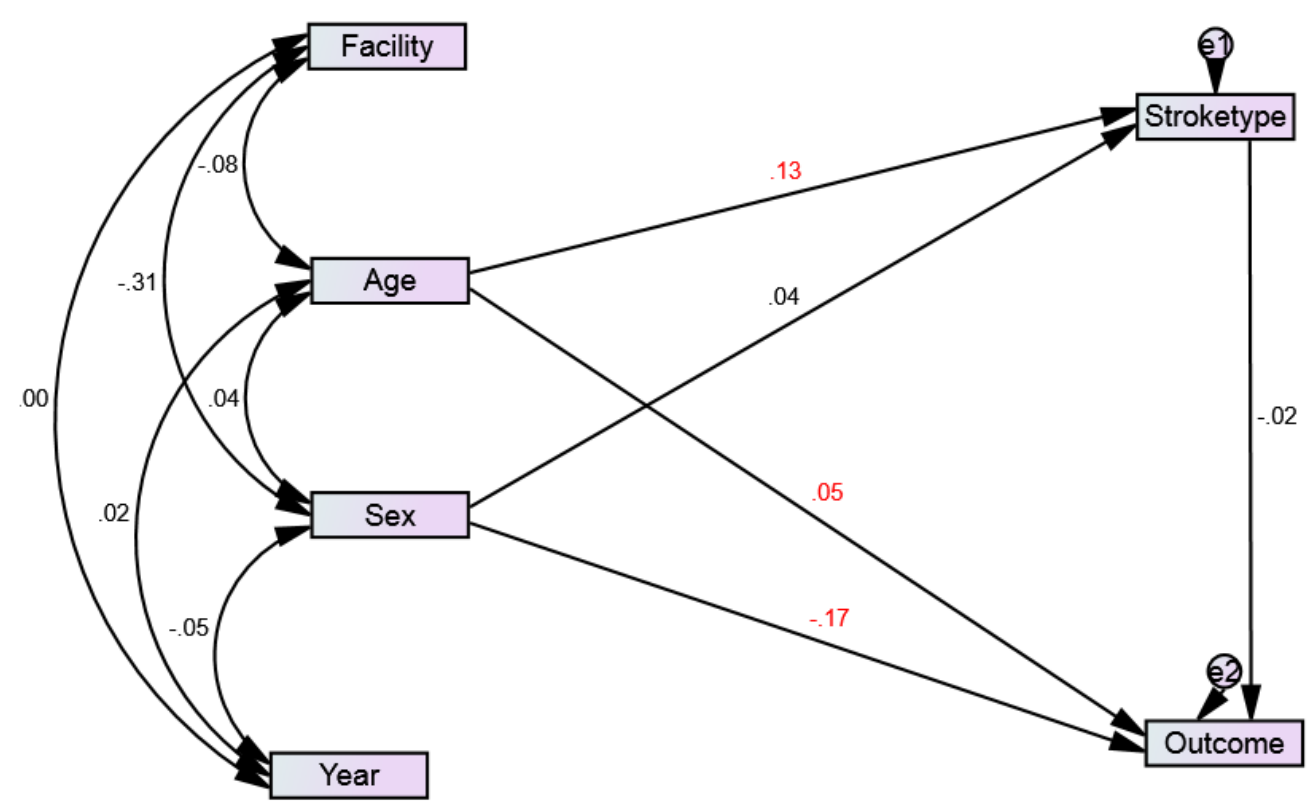

Figure A1: SPSS-Amos output for the SEM standardized pathways (z-statistic) Note: 1. Red colours indicates low to moderate estimates; 2 . GFI=0.982, CFI=0.739; 3. Facility and year were statistically controlled.

Table A1: Regression weight and standardized (z-statistics) estimates in the SEM analysis

\begin{tabular}{|c|c|c|c|c|c|c|c|}
\hline \multicolumn{3}{|c|}{ Model Variable } & \multirow{2}{*}{$\begin{array}{l}\text { Estimate } \\
0.098\end{array}$} & \multirow{2}{*}{$\begin{array}{l}\text { S.E. } \\
0.017\end{array}$} & \multirow{2}{*}{$\begin{array}{l}\text { Z-Estimate } \\
0.132\end{array}$} & \multirow{2}{*}{$\begin{array}{l}\text { C.R. } \\
5.836\end{array}$} & \multirow{2}{*}{$\begin{array}{c}\text { P-value } \\
<0.001\end{array}$} \\
\hline Stroke type & $<--$ & Age group & & & & & \\
\hline Stroke type & $<--$ & Sex & 0.037 & 0.02 & 0.043 & 1.884 & 0.06 \\
\hline Outcome & $<--$ & Age group & 0.066 & 0.032 & 0.047 & 2.07 & 0.038 \\
\hline Outcome & $<--$ & Sex & -0.273 & 0.037 & -0.167 & -7.394 & $<0.001$ \\
\hline Outcome & $<---$ & Stroke type & -0.034 & 0.043 & -0.018 & -0.792 & 0.428 \\
\hline
\end{tabular}

Note: 1. Z-standardised score; 2. S.E-Standard error; C.R-critical ratio; P-probability; ${ }^{* * *} p<0.001 ; 3$. Sex, CD4 count on starting HAART, and Duration on HAART were statistically controlled.

\section{References}

[1] D. Theofanidis, "From Apoplexy to Brain Attack, a Historical Perspective on Stroke to Date," 2014, doi: 10.4172/2167-1168.1000e121.

[2] E. Engelhardt, "Apoplexia, doença cerebrovascular e acidente vascular cerebral: Evolução histórica dos termos e definições," Dementia e Neuropsychologia, vol. 11, no. 4. Academia Brasileira de Neurologia, pp. 449-453, Oct. 01, 2017, doi: 10.1590/1980-57642016dn11-040016.

[3] A. P. Coupland, A. Thapar, M. I. Qureshi, H. Jenkins, and A. H. Davies, “The definition of stroke," J. R. Soc. Med., vol. 110, no. 1, pp. 9-12, Jan. 2017, doi: 10.1177/0141076816680121.

[4] M. L. Nilsen, "A historical account of stroke and the evolution of nursing care for stroke patients," $J$. Neurosci. Nurs., vol. 42, no. 1, pp. 19-27, Feb. 2010, doi: 10.1097/JNN.0b013e3181c1fdad.

[5] H. Schutta and H. Howe, "Seventeenth century concepts of 'apoplexy' as reflected in Bonet's 'Sepulchretum,'” Journal of the History of the Neurosciences, vol. 15, no. 3. J Hist Neurosci, pp. 250-268, Sep. 01, 2006, doi: 10.1080/09647040500403312.

[6] E. S. Donkor, "Stroke in the 21st Century: A Snapshot of the Burden, Epidemiology, and Quality of Life," 
Stroke Research and Treatment, vol. 2018. Hindawi Limited, 2018, doi: 10.1155/2018/3238165.

[7] A. Puthenpurakal and J. Crussell, “Stroke 1: definition, burden, risk factors and diagnosis," Nurs. Times, vol. 113, no. 11, pp. 43-47, 2017.

[8] R. L. Sacco et al., "An updated definition of stroke for the 21st century: A statement for healthcare professionals from the American heart association/American stroke association," Stroke, vol. 44, no. 7, pp. 2064-2089, 2013, doi: 10.1161/STR.0b013e318296aeca.

[9] S. Hatano, "Experience from a multicentre stroke register: a preliminary report.," Bull. World Health Organ., vol. 54, no. 5, pp. 541-553, 1976.

[10] K. Aho, P. Harmsen, S. Hatano, J. Marquardsen, V. E. Smirnov, and T. Strasser, “Cerebrovascular disease in the community: results of a WHO collaborative study," Bull. World Health Organ., vol. 58, no. 1, pp. 113130, 1980, Accessed: May 26, 2021. [Online]. Available: /pmc/articles/PMC2395897/?report=abstract.

[11] G. Department of Information, Evidence and Research WHO, "WHO methods and data sources for country-level causes of death 2000-2015 Global Health Estimates Technical Paper WHO/HIS/IER/GHE/2016.3," World Heal. Organ., no. January, pp. 1-81, 2017, [Online]. Available: http://www.ncbi.nlm.nih.gov/pubmed/25378742\%5Cnhttp://www.pubmedcentral.nih.gov/articlerender.f cgi?artid=PMC4221770.

[12] WHO, "Guidelines for Management of Stroke," Who, pp. 1-42, 2012.

[13] G. Namale et al., "Risk Factors for Hemorrhagic and Ischemic Stroke in Sub-Saharan Africa," Journal of Tropical Medicine, vol. 2018. Hindawi Limited, 2018, doi: 10.1155/2018/4650851.

[14] J. H. Chin and N. Vora, “The global burden of neurologic diseases," Neurology, vol. 83, no. 4. Lippincott Williams and Wilkins, pp. 349-351, Jul. 22, 2014, doi: 10.1212/WNL.0000000000000610.

[15] V. L. Feigin et al., "Burden of Neurological Disorders across the US from 1990-2017: A Global Burden of Disease Study," JAMA Neurol., 2020, doi: 10.1001/jamaneurol.2020.4152.

[16] G. B. Lim, "Public health: Global burden of cardiovascular disease," Nature Reviews Cardiology, vol. 10, no. 2. p. 59, Feb. 2013, doi: 10.1038/nrcardio.2012.194.

[17] C. J. L. Murray et al., "Disability-adjusted life years (DALYs) for 291 diseases and injuries in 21 regions, 1990-2010: A systematic analysis for the Global Burden of Disease Study 2010," Lancet, vol. 380, no. 9859, pp. 2197-2223, Dec. 2012, doi: 10.1016/S0140-6736(12)61689-4.

[18] K. Steinbeck, M. Kohn, and R. Webster, "Common Neurological Disorders," in A Clinical Handbook in Adolescent Medicine, WORLD SCIENTIFIC, 2013, pp. 491-507.

[19] R. P. Lisak, “Global perspectives," Neurology, vol. 82, no. 2, pp. 172-173, 2014, doi: 10.1212/WNL.0000000000000010.

[20] C. A. Jackson, G. D. Mishra, L. Tooth, J. Byles, and A. Dobson, “Moderate agreement between self-reported stroke and hospital-recorded stroke in two cohorts of Australian women: A validation study," BMC Med. Res. Methodol., vol. 15, no. 1, p. 7, Dec. 2015, doi: 10.1186/1471-2288-15-7.

[21] H. Krueger, J. Koot, R. E. Hall, C. O'Callaghan, M. Bayley, and D. Corbett, "Prevalence of Individuals Experiencing the Effects of Stroke in Canada: Trends and Projections," Stroke., vol. 46, no. 8, pp. 2226-2231, Aug. 2015, doi: 10.1161/STROKEAHA.115.009616.

[22] C. L. Gooch, E. Pracht, and A. R. Borenstein, "The burden of neurological disease in the United States: A summary report and call to action," Annals of Neurology, vol. 81, no. 4. John Wiley and Sons Inc., pp. 479484, Apr. 01, 2017, doi: 10.1002/ana.24897.

[23] P. Scott, "NATIONAL INSTITUTE OF NEUROLOGICAL DISORDERS AND STROKE Address : Mission : Director : Legislative Contact:," no. April, 2005. 
[24] M. D. Connor, R. Walker, G. Modi, and C. P. Warlow, "Burden of stroke in black populations in subSaharan Africa," Lancet Neurology, vol. 6, no. 3. Lancet Publishing Group, pp. 269-278, 2007, doi: 10.1016/S1474-4422(07)70002-9.

[25] M. C. Ezejimofor et al., "Stroke survivors in Nigeria: A door-to-door prevalence survey from the Niger Delta region," J. Neurol. Sci., vol. 372, pp. 262-269, Jan. 2017, doi: 10.1016/j.jns.2016.11.059.

[26] A. C. Onwuchekwa, C. Tobin-West, and S. Babatunde, "Prevalence and risk factors for stroke in an adult population in a rural community in the Niger Delta, South-South Nigeria," J. Stroke Cerebrovasc. Dis., vol. 23, no. 3, pp. 505-510, Mar. 2014, doi: 10.1016/j.jstrokecerebrovasdis.2013.04.010.

[27] V. L. Feigin et al., "Global and regional burden of stroke during 1990-2010: Findings from the Global Burden of Disease Study 2010," Lancet, vol. 383, no. 9913, pp. 245-255, 2014, doi: 10.1016/S01406736(13)61953-4.

[28] U.S. Department of Health and Human Services (HHS), "Organ Donation and African Americans - The Office of Minority Health," 2020. https://www.minorityhealth.hhs.gov/omh/browse.aspx?lvl=4\&lvlid=28 (accessed May 25, 2021).

[29] M. Owolabi et al., "The burden of stroke in Africa: a glance at the present and a glimpse into the future: review article," Cardiovasc. J. Afr., vol. 26, no. 2, pp. S27-S38, Apr. 2015, doi: 10.5830/CVJA-2015-038.

[30] R. W. Walker, M. Rolfe, P. J. Kelly, M. O. George, and O. F. W. James, “Mortality and recovery after stroke in The Gambia," Stroke, vol. 34, no. 7, pp. 1604-1609, Jul. 2003, doi: 10.1161/01.STR.0000077943.63718.67.

[31] B. Chioma Ekeh, "Challenges of the Management of Stroke in Sub Saharan Africa: Evaluating Awareness, Access and Action," 2017, doi: 10.4172/2472-100X.1000128.

[32] F. S. Sarfo et al., "Long-Term Outcomes of Stroke in a Ghanaian Outpatient Clinic," J. Stroke Cerebrovasc. Dis., vol. 27, no. 4, pp. 1090-1099, Apr. 2018, doi: 10.1016/j.jstrokecerebrovasdis.2017.11.017.

[33] M. Danesi, N. Okubadejo, and F. Ojini, "Prevalence of stroke in an urban, mixed-income community in Lagos, Nigeria," Neuroepidemiology, vol. 28, no. 4, pp. 216-223, Oct. 2007, doi: 10.1159/000108114.

[34] B. Osuntokun et al., "Neurological disorders in Nigerian Africans: a community-based study," Acta Neurol. Scand., vol. 75, no. 1, pp. 13-21, 1987, doi: 10.1111/j.1600-0404.1987.tb07883.x.

[35] E. O. Sanya, O. O. Desalu, F. Adepoju, S. A. Aderibigbe, A. Shittu, and O. Olaosebikan, "Prevalence of stroke in three semi-urban communities in middle-belt region of Nigeria: A door to door survey," Pan Afr. Med. J., vol. 20, Jan. 2015, doi: 10.11604/pamj.2015.20.33.4594.

[36] E. Sagui et al., "Ischemic and hemorrhagic strokes in Dakar, Senegal: A hospital-based study," Stroke, vol. 36, no. 9, pp. 1844-1847, Sep. 2005, doi: 10.1161/01.STR.0000177864.08516.47.

[37] L. C. A. Rutten-Jacobs et al., "Cardiovascular disease is the main cause of long-term excess mortality after ischemic stroke in young adults," Hypertension, vol. 65, no. 3, pp. 670-675, Mar. 2015, doi: 10.1161/HYPERTENSIONAHA.114.04895.

[38] A. Onwuchewa, H. Bellgam, and G. Asekomeh, "Stroke at the University of Port Harcourt Teaching Hospital, Rivers State, Nigeria," Trop. Doct., vol. 39, no. 3, pp. 150-152, 2009, doi: 10.1258/td.2008.080285.

[39] R. Nall, “Types of Strokes: Causes, Symptoms, and Treatments," Healthline, 2018. https://www.healthline.com/health/stroke-types\#types (accessed Apr. 02, 2021).

[40] E. Sanya, K. Wahab, A. Bello, W. Alaofin, and B. Ademiluyi, "In-hospital stroke mortality and its predictors within one month of ictus: Result from a tertiary hospital in Ilorin, middle belt Nigeria," Sub-Saharan African J. Med., vol. 2, no. 4, p. 165, 2015, doi: 10.4103/2384-5147.172439.

[41] D. Mozaffarian, "Prevalence of stroke by age and sex (National Health and Nutrition Examination Survey: 2009-2012).," pp. 2009-2012, 2015. 
[42] J. H. Chin, "Global perspectives," Neurology, vol. 78, no. 13. Lippincott Williams and Wilkins, pp. 10071008, Mar. 27, 2012, doi: 10.1212/WNL.0b013e318248df95.

[43] M. Goyal, M. Goyal, J. M. Ospel, and J. M. Ospel, "Stroke Systems of Care: Current State of Affairs and Future Directions," Stroke, pp. 1928-1931, 2020, doi: 10.1161/STROKEAHA.120.030288.

[44] A. Avan et al., "Socioeconomic status and stroke incidence, prevalence, mortality, and worldwide burden: an ecological analysis from the Global Burden of Disease Study 2017," BMC Med., vol. 17, no. 1, p. 191, 2019, doi: 10.1186/s12916-019-1397-3.

[45] M. El-Hajj, P. Salameh, S. Rachidi, and H. Hosseini, "The epidemiology of stroke in the Middle East," European Stroke Journal, vol. 1, no. 3. SAGE Publications Ltd, pp. 180-198, Sep. 01, 2016, doi: $10.1177 / 2396987316654338$.

[46] M. Katan and A. Luft, “Global Burden of Stroke,” Semin. Neurol., vol. 38, no. 2, pp. 208-211, Apr. 2018, doi: 10.1055/s-0038-1649503.

[47] M. Owolabi et al., "Stroke in Indigenous Africans, African Americans, and European Americans: Interplay of Racial and Geographic Factors," Stroke, vol. 48, no. 5, pp. 1169-1175, May 2017, doi: 10.1161/STROKEAHA.116.015937.

[48] W. Johnson, O. Onuma, M. Owolabi, and S. Sachdev, "Stroke: a global response is needed," Bull. World Health Organ., vol. 94, no. 9, pp. 634-634A, Sep. 2016, doi: 10.2471/BLT.16.181636.

[49] Y. Zhang, A. M. Chapman, M. Plested, D. Jackson, and F. Purroy, "The incidence, prevalence, and mortality of stroke in France, Germany, Italy, Spain, the UK, and the US: A literature review," Stroke Research and Treatment. 2012, doi: 10.1155/2012/436125.

[50] T. Vos et al., "Global burden of 369 diseases and injuries in 204 countries and territories, 1990-2019: a systematic analysis for the Global Burden of Disease Study 2019," Lancet, vol. 396, no. 10258, pp. 1204-1222, 2020, doi: 10.1016/S0140-6736(20)30925-9.

[51] S. G. Wannamethee, "Risk Factors for Stroke," European Journal of Preventive Cardiology, vol. 6, no. 4. pp. 199-202, 1999, doi: 10.1177/204748739900600401.

[52] Q. Cui and N. A. Naikoo, "Modifiable and non-modifiable risk factors in ischemic stroke: A meta-analy," Afr. Health Sci., vol. 19, no. 2, pp. 2121-2129, 2019, doi: 10.4314/ahs.v19i2.36.

[53] A. K. Boehme, C. Esenwa, and M. S. V. Elkind, "Stroke Risk Factors, Genetics, and Prevention," Circ. Res., vol. 120, no. 3, pp. 472-495, 2017, doi: 10.1161/CIRCRESAHA.116.308398.

[54] P. K. Georgakakos, M. B. Swanson, A. Ahmed, and N. M. Mohr, "Rural Stroke Patients Have Higher Mortality: An Improvement Opportunity for Rural Emergency Medical Services Systems," J. Rural Heal., vol. 0, pp. 1-11, Aug. 2020, doi: 10.1111/jrh.12502.

[55] J. D. Pandian and P. Sudhan, "Stroke Epidemiology and Stroke Care Services in India," J. Stroke, vol. 15, no. 3, p. 128, 2013, doi: 10.5853/jos.2013.15.3.128.

[56] T. Ojo et al., "Adapting a skills-based stroke prevention intervention for communities in Ghana: a qualitative study," Implement. Sci. Commun., vol. 1, no. 1, p. 104, Dec. 2020, doi: 10.1186/s43058-020-000848.

[57] Stroke 411, “Non-modifiable Stroke Risk Factors," 2021. https://stroke411.com/about-stroke/nonmodifiable-stroke-risk-factors/ (accessed Mar. 05, 2021).

[58] R. V. Krishnamurthi et al., "Global and regional burden of first-ever ischaemic and haemorrhagic stroke during 1990-2010: Findings from the Global Burden of Disease Study 2010," Lancet Glob. Heal., vol. 1, no. 5, 2013, doi: 10.1016/S2214-109X(13)70089-5.

[59] M. J. O'Donnell et al., "Global and regional effects of potentially modifiable risk factors associated with 
acute stroke in 32 countries (INTERSTROKE): a case-control study," Lancet, vol. 388, no. 10046, pp. 761775, Aug. 2016, doi: 10.1016/S0140-6736(16)30506-2.

[60] G. Santulli, "Epidemiology of cardiovascular disease in the 21st century: Updated updated numbers and updated facts," J. Cardiovasc. Dis. Res., vol. 1, no. 1, 2013, Accessed: May 25, 2021. [Online]. Available: https://einstein.pure.elsevier.com/en/publications/epidemiology-of-cardiovascular-disease-in-the21supstsup-century-.

[61] A. Pandey et al., "Association between midlife cardiorespiratory fitness and risk of stroke: The cooper center longitudinal study," Stroke, vol. 47, no. 7, pp. 1720-1726, 2016, doi: 10.1161/STROKEAHA.115.011532.

[62] A. Alloubani, A. Saleh, and I. Abdelhafiz, "Hypertension and diabetes mellitus as a predictive risk factors for stroke," Diabetes and Metabolic Syndrome: Clinical Research and Reviews, vol. 12, no. 4. Elsevier Ltd, pp. 577-584, Jul. 01, 2018, doi: 10.1016/j.dsx.2018.03.009.

[63] S. Cruz-Flores et al., "Racial-ethnic disparities in stroke care: The American experience: A statement for healthcare professionals from the American Heart Association/American Stroke Association," Stroke, vol. 42, no. 7, pp. 2091-2116, Jul. 2011, doi: 10.1161/STR.0b013e3182213e24.

[64] Centers for Disease Control and Prevention, "Family history and other characteristics that increase risk for high blood pressure," High Blood Press., 2016, Accessed: May 25, 2021. [Online]. Available: https://www.cdc.gov/stroke/family_history.htm.

[65] R. Tekle-Haimanot, E. B. Ngoungou, and D. Kibru, Epidemiology of neurological disorders in sub-saharan Africa. Elsevier Inc., 2017.

[66] CIOMS, International Ethical Guidelines for Health-related Research Involving Humans Fourth Edition. Geneva, no. February. 2016.

[67] L. Liberale et al., "Ischemic stroke across sexes: What is the status quo?," Frontiers in Neuroendocrinology, vol. 50. Academic Press Inc., pp. 3-17, Jul. 01, 2018, doi: 10.1016/j.yfrne.2018.05.001.

[68] M. V. Vyas et al., "Stroke Incidence by Sex Across the Lifespan,” Stroke, vol. 52, no. 2, pp. 447-451, Jan. 2021, doi: 10.1161/STROKEAHA.120.032898.

[69] B. Manwani and L. D. McCullough, "Sexual dimorphism in ischemic stroke: Lessons from the laboratory," Women's Health, vol. 7, no. 3. pp. 319-339, May 2011, doi: 10.2217/whe.11.22.

[70] M. Roy-O'Reilly and L. D. McCullough, "Age and sex are critical factors in ischemic stroke pathology," Endocrinology, vol. 159, no. 8, pp. 3120-3131, Aug. 2018, doi: 10.1210/en.2018-00465.

[71] C. Ter Ong et al., "Sex-related differences in the risk factors for in-hospital mortality and outcomes of ischemic stroke patients in rural areas of Taiwan," PLoS One, vol. 12, no. 9, Sep. 2017, doi: 10.1371/journal.pone.0185361.

[72] M. S. Ekker, J. I. Verhoeven, I. Vaartjes, W. M. T. Jolink, C. J. M. Klijn, and F. E. De Leeuw, "Association of Stroke among Adults Aged 18 to 49 Years with Long-term Mortality," JAMA - J. Am. Med. Assoc., vol. 321, no. 21, pp. 2113-2123, Jun. 2019, doi: 10.1001/jama.2019.6560.

[73] S. Koton et al., "Stroke incidence and mortality trends in US communities, 1987 to 2011," JAMA - J. Am. Med. Assoc., vol. 312, no. 3, pp. 259-268, Jul. 2014, doi: 10.1001/jama.2014.7692.

[74] L. C. A. Rutten-Jacobs et al., "Long-term mortality after stroke among adults aged 18 to 50 years," JAMA J. Am. Med. Assoc., vol. 309, no. 11, pp. 1136-1144, Mar. 2013, doi: 10.1001/jama.2013.842.

[75] C. M. Kosar, L. Loomer, N. B. Ferdows, A. N. Trivedi, O. A. Panagiotou, and M. Rahman, “Assessment of Rural-Urban Differences in Postacute Care Utilization and Outcomes Among Older US Adults," JAMA Netw. open, vol. 3, no. 1, p. e1918738, Jan. 2020, doi: 10.1001/jamanetworkopen.2019.18738.

[76] V. L. Feigin, C. M. Lawes, D. A. Bennett, S. L. Barker-Collo, and V. Parag, “Worldwide stroke incidence 
and early case fatality reported in 56 population-based studies: a systematic review," Lancet Neurol., vol. 8, no. 4, pp. 355-369, 2009, doi: 10.1016/S1474-4422(09)70025-0.

[77] K. L. Furie et al., "Guidelines for the prevention of stroke in patients with stroke or transient ischemic attack: A guideline for healthcare professionals from the American Heart Association/American stroke association," Stroke, vol. 42, no. 1, pp. 227-276, Jan. 2011, doi: 10.1161/STR.0b013e3181f7d043.

[78] M. S. Elkind and R. L. Sacco, "Stroke risk factors and stroke prevention," Seminars in Neurology, vol. 18, no. 4. Thieme Medical Publishers, Inc., pp. 429-440, 1998, doi: 10.1055/s-2008-1040896.

[79] J. S. Tanaka and G. J. Huba, "A fit index for covariance structure models under arbitrary GLS estimation," Br. J. Math. Stat. Psychol., vol. 38, no. 2, pp. 197-201, Nov. 1985, doi: 10.1111/j.2044-8317.1985.tb00834.x.

[80] P. M. Bentler, "Comparative fit indexes in structural models," Psychol. Bull., vol. 107, no. 2, pp. 238-246, 1990, doi: 10.1037/0033-2909.107.2.238.

[81] S. Parry, "Fit Indices commonly reported for CFA and SEM," Cornell Univ. Cornell Stat. Consult. Unit, p. 2, 2020, [Online]. Available: www.cscu.cornell.edu/news/handouts.php.

[82] W. G. Cochran, “The $\$ \backslash \operatorname{chi}^{\wedge} 2 \$$ Test of Goodness of Fit,” Ann. Math. Stat., vol. 23, no. 3, pp. 315-345, Sep. 1952, doi: 10.1214/aoms/1177729380.

[83] H. Gulliksen and J. W. Tukey, "Reliability for the law of comparative judgment," Psychometrika, vol. 23, no. 2, pp. 95-110, Jun. 1958, doi: 10.1007/BF02289008.

[84] "Stroke Prevalence and Risk Factors." https://www.uspharmacist.com/article/stroke-prevalence-and-riskfactors (accessed Feb. 12, 2021).

[85] D. Lemogoum, J. P. Degaute, and P. Bovet, "Stroke prevention, treatment, and rehabilitation in SubSaharan Africa," American Journal of Preventive Medicine, vol. 29, no. 5 SUPPL. 1. pp. 95-101, Dec. 2005, doi: 10.1016/j.amepre.2005.07.025.

[86] B. B. Simmons, B. Cirignano, and A. B. Gadegbeku, “Transient Ischemic Attack: Part I. Diagnosis and Evaluation," Sep. 2012. Accessed: Mar. 05, 2021. [Online]. Available: www.aafp.org/afp.

[87] P. Appelros, I. Nydevik, and M. Viitanen, "Poor outcome after first-ever stroke: Predictors for death, dependency, and recurrent stroke within the first year," Stroke, vol. 34, no. 1, pp. 122-126, Jan. 2003, doi: 10.1161/01.STR.0000047852.05842.3C.

[88] L. F. Owolabi and A. Ibrahim, "Stroke in Young Adults: A Prospective Study from Northwestern Nigeria," ISRN Neurol., vol. 2012, pp. 1-5, Feb. 2012, doi: 10.5402/2012/468706.

[89] C. O. Johnson et al., "Global, regional, and national burden of stroke, 1990-2016: a systematic analysis for the Global Burden of Disease Study 2016," Lancet Neurol., vol. 18, no. 5, pp. 439-458, May 2019, doi: 10.1016/S1474-4422(19)30034-1.

[90] F. S. Sarfo et al., "Stroke among young West Africans: Evidence from the SIREN (stroke investigative research and educational network) large multisite case-control study," Stroke, vol. 49, no. 5, pp. 1116-1120, 2018, doi: 10.1161/STROKEAHA.118.020783.

[91] D. Mozaffarian et al., "Heart disease and stroke statistics-2015 update : A report from the American Heart Association," Circulation, vol. 131, no. 4, pp. e29-e39, Jan. 2015, doi: 10.1161/CIR.0000000000000152.

[92] S. L. Gall et al., "Sex differences in presentation, severity, and management of stroke in a population-based study.," Neurology, vol. 74, no. 12, pp. 975-81, Mar. 2010, doi: 10.1212/WNL.0b013e3181d5a48f.

[93] D. G. Jamieson and M. Skliut, "Stroke in Women: What is different," Current Atherosclerosis Reports, vol. 12, no. 4. Springer, pp. 236-243, Jul. 21, 2010, doi: 10.1007/s11883-010-0118-3.

[94] C. D. Bushnell et al., "Sex differences in stroke: Challenges and opportunities," Journal of Cerebral Blood Flow and Metabolism, vol. 38, no. 12. SAGE Publications Ltd, pp. 2179-2191, Dec. 01, 2018, doi: 


\section{$10.1177 / 0271678 \times 18793324$.}

[95] C. D. Bushnell et al., "Sex differences in quality of life after ischemic stroke," Neurology, vol. 82, no. 11, pp. 922-931, Mar. 2014, doi: 10.1212/WNL.0000000000000208.

[96] M. J. Reeves et al., “Sex differences in stroke: epidemiology, clinical presentation, medical care, and outcomes," The Lancet Neurology, vol. 7, no. 10. Lancet Neurol, pp. 915-926, Oct. 2008, doi: 10.1016/S14744422(08)70193-5.

[97] M. Ebinger et al., "Effect of the Use of Ambulance-Based Thrombolysis on Time to Thrombolysis in Acute Ischemic Stroke," JAMA, vol. 311, no. 16, p. 1622, Apr. 2014, doi: 10.1001/jama.2014.2850.

[98] B. M. Demaerschalk et al., "Contemporary Management of Acute Ischemic Stroke Across the Continuum: From TeleStroke to Intra-Arterial Management," Mayo Clinic Proceedings, vol. 95, no. 7. Elsevier Ltd, pp. 1512-1529, Jul. 01, 2020, doi: 10.1016/j.mayocp.2020.04.002.

[99] D. T. Lackland et al., "Factors influencing the decline in stroke mortality a statement from the american heart association/american stroke association," Stroke, vol. 45, no. 1, pp. 315-353, Jan. 2014, doi: 10.1161/01.str.0000437068.30550.cf.

[100] L. Djingri Labodi et al., "Hospitalized patients care pathway for stroke and its determinants in a reference hospital in ouagadougou (Burkina faso)," Blood, Hear. Circ., vol. 1, no. 4, 2017, doi: 10.15761/bhc.1000123.

[101] M. Liu, S. Dziennis, P. D. Hurn, and N. J. Alkayed, "Mechanisms of gender-linked ischemic brain injury," Restorative Neurology and Neuroscience, vol. 27, no. 3. pp. 163-179, 2009, doi: 10.3233/RNN-2009-0467.

[102] C. Sarti, D. Rastenyte, Z. Cepaitis, and J. Tuomilehto, "International trends in mortality from stroke, 1968 to 1994," Stroke, vol. 31, no. 7, pp. 1588-1601, 2000, doi: 10.1161/01.STR.31.7.1588.

[103] J. Li and L. D. McCullough, "Sex differences in minocycline-induced neuroprotection after experimental stroke," J. Cereb. Blood Flow Metab., vol. 29, no. 4, pp. 670-674, Apr. 2009, doi: 10.1038/jcbfm.2009.3.

[104] J. F. Ortiz et al., "Minocycline and Magnesium As Neuroprotective Agents for Ischemic Stroke: A Systematic Review.," Cureus, vol. 12, no. 12, p. e12339, Dec. 2020, doi: 10.7759/cureus.12339.

[105] M. R. Amiri-Nikpour, S. Nazarbaghi, M. Hamdi-Holasou, and Y. Rezaei, “An open-label evaluator-blinded clinical study of minocycline neuroprotection in ischemic stroke: gender-dependent effect," Acta Neurol. Scand., vol. 131, no. 1, pp. 45-50, Jan. 2015, doi: 10.1111/ane.12296.

[106] Internet Stroke Center, “Stroke Statistics," 2021. http://www.strokecenter.org/patients/aboutstroke/stroke-statistics/ (accessed Apr. 02, 2021).

[107] M. Heron, "Deaths: Leading Causes for 2014.," Natl. vital Stat. reports from Centers Dis. Control Prev. Natl. Cent. Heal. Stat. Natl. Vital Stat. Syst., vol. 65, no. 5, pp. 1-96, Jun. 2016.

[108] D. J. Moritz, P. J. Fox, P. A. Luscombe, and H. C. Kraemer, “Neurological and psychiatric predictors of mortality in patients with Alzheimer disease in California," Arch. Neurol., vol. 54, no. 7, pp. 878-885, 1997, doi: 10.1001/archneur.1997.00550190066016.

[109] S. Barker-Collo et al., "Improving adherence to secondary stroke prevention strategies through motivational interviewing: Randomized controlled trial," Stroke, vol. 46, no. 12, pp. 3451-3458, Dec. 2015, doi: 10.1161/STROKEAHA.115.011003. 